\title{
TRÊS PREMISSAS PERNICIOSAS NO ESTUDO DO GUETO NORTE-AMERICANO
}

Loïc J. D. Wacquant

\begin{abstract}
"O que terá levado os homens a tomar como verdade essas proposições ou essas crenças mitológicas? Terá sido por confrontá-las com uma dada realidade? De modo algum! [...]. Nossas idéias, nossas crenças é que, ao contrário, conferem realidade aos objetos de pensamento". Émile Durkheim, Pragmatisme et Sociologie, 1913.
\end{abstract}

Três tendências ou premissas solidamente arraigadas têm prevalecido no recente debate sobre divisão racial e pobreza urbana nos Estados Unidos. Elas estão enraizadas em velhas concepções norte-americanas que definem os pobres - particularmente os negros pobres - como moralmente deficientes e a cidade como um lugar nefasto que desintegra e corrompe a vida social, especialmente no caso das classes baixas (Boyer 1978; Katz 1983; Patterson 1986; Fishman 1988). Dotadas da plausibilidade conferida pelo peso da história cultural e da inércia intelectual, reforçadas por uma linguagem nacional individualista que desenfatiza as classes e trata de modo eufêmico a dominação étnico-racial, tais premissas constituem as pedras angulares da doxa acadêmica atual sobre o assunto. Por isso mesmo não costumam ser questionadas nem refutadas ${ }^{1}$. Mas essas crenças subjacentes mutilam e distorcem nossa compreensão do processo de (re)articulação entre cor, classe e local de moradia atualmente em curso nas metrópoles norte-americanas.

A primeira e mais recente tendência é a diluição da noção de gueto, que passa a designar tão-somente uma área urbana de pobreza extrema e generalizada. A conseqüência disso é ocultar a natureza e o fundamento racial da pobreza aí existente, além de despojar o conceito de gueto de seu significado histórico e de seus conteúdos sociológicos. A segunda crença, já centenária, é a idéia de que o gueto é uma formação social "desorganizada", mais corretamente analisável pela ótica da falta e das deficiências (individuais ou coletivas) do que pela identificação positiva 
dos princípios que fundamentam sua ordem interna e regulam seu modo específico de funcionamento. A terceira, derivada da idéia de desorganização, é a tendência a exotizar o gueto e seus moradores, ou seja, a destacar os aspectos mais extremos e incomuns da vida no gueto, vistos de fora e de cima, isto é, do ponto de vista do dominante.

Cada uma dessas premissas está associada a uma série de erros e incorreções analíticas tão usuais que ou não são notados ou, pior ainda, são vistos como inerentes à própria natureza do fenômeno. Em conjunto, elas constituem um enorme "obstáculo epistemológico" (Bachelard 1938) à construção de uma sociologia teoricamente rigorosa e empiricamente precisa do conflito racial e da marginalidade urbana nos Estados Unidos de hoje. Todas concorrem para a dissolução das fronteiras entre a percepção do senso comum e a análise científica, entre realidades complexas e controversas a explicar e o que as pessoas desejam pensar sobre

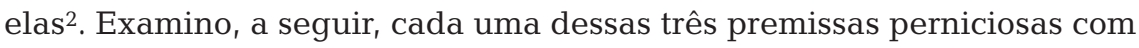
a intenção de oferecer um prolegômeno crítico a essa sociologia.

\section{Recuperando uma concepção institucionalista do gueto}

As discussões recentes sobre raça e pobreza nos bairros centrais das cidades norte-americanas tendem a equiparar o gueto a qualquer área de grande pobreza, sem levar em conta sua população e as características de sua organização social. Jargowski e Bane oferecem um bom exemplo dessa elisão da dimensão institucional e racial da noção de gueto, ao escreverem que:

\footnotetext{
“Definimos um gueto como uma área onde a taxa global de pobreza, de acordo com o censo demográfico, é maior do que $40 \%$. Os pobres do gueto são, portanto, os pobres oriundos de qualquer grupo racial ou étnico vivendo nessas regiões de alta pobreza [...]. Visitas feitas a diversas cidades confirmaram que o critério dos $40 \%$ permite uma razoável identificação de áreas que se parecem com guetos em termos de condições de moradia. Além disso, as áreas selecionadas pelo critério dos $40 \%$ correspondiam de perto a bairros que as autoridades públicas e os funcionários dos escritórios locais de recenseamento consideravam como guetos [...]. É importante distinguir nossa definição de áreas de gueto, baseada no critério de pobreza, de uma definição fundada na composição racial. Nem todas as áreas de maioria negra são guetos, segundo nossa definição, assim como nem todos os guetos são negros" (Jargowski e Bane 1991:239 e 241, ênfases minhas).
} 
Essa (re)definição do termo merece ser analisada com atenção, pois concentra quase todos os defeitos que têm desfigurado os usos mais recentes do conceito: (1) é totalmente arbitrária (como os próprios autores reconhecem na p. 239): por que excluir as zonas rurais e tomar como base de definição as regiões censitárias? Por que utilizar como padrão de medida a "linha de pobreza" oficial e uma taxa de $40 \%$ de pobres como ponto de corte? (2) é a-sociológica, na medida em que se limita à renda e às condições visíveis de habitação, não levando em consideração o padrão de estruturação das relações sociais que as determinam; (3) é ostensivamente "desracializada", ao designar apenas os enclaves urbanos pobres de maioria negra, virtualmente excluindo as áreas habitadas por brancos pobres; (4) é essencialmente burocrática, derivada de categorias administrativas, já que sua viabilidade depende da existência e da disponibilidade de dados governamentais; finalmente, (5) a definição consiste em uma terrível confusão entre um conceito histórico-analítico e uma noção leiga sustentada pelas elites da cidade e do Estado.

Tudo isso implica esquecer que a maior parte das áreas urbanas de "pobreza extrema" (seja qual for o parâmetro) que compõem o Rustbelt dos Estados Unidos é uma herança direta dos antigos "Cinturões Negros" das cidades. Dizer que essas áreas são guetos porque são pobres é inverter a linha de causalidade histórica e social: é porque foram e são guetos que o desemprego e a miséria atingem aí níveis extraordinariamente intensos e persistentes - não o contrário. Chamar de gueto qualquer área que apresente uma taxa elevada ou uma alta concentração de pobreza não é só arbitrário e empiricamente problemático; é também retirar do termo seu significado histórico e destituí-lo de seu alcance sociológico, impedindo a análise dos critérios e processos através dos quais a exclusão se realiza nele. Mais ainda, encobre-se assim o fato de os negros serem o único grupo que passou pela experiência da "guetização" na sociedade norte-americana, isto é, uma separação residencial total, permanente e involuntária, fundada na casta como base para o desenvolvimento de uma estrutura social paralela (e inferior) ${ }^{3}$.

Como sugerem as origens históricas e o uso historiográfico do termo (Cooperman e Curiel 1990), um gueto não é apenas uma entidade topográfica ou um agregado de famílias e indivíduos pobres, mas uma forma institucional, uma articulação espacial, historicamente determina$\mathrm{da}$, de mecanismos de fechamento e controle étnico-racial (Wacquant 1991) ${ }^{4}$. Em termos ideal-típicos, um gueto pode ser caracterizado como uma formação socioespacial uniforme limitada racial e/ou culturalmente. Baseia-se (1) na exclusão forçada de (2) uma população "negativa- 
mente tipificada" (Weber 1978:385-387), como os judeus na Europa medieval e os afro-americanos nos Estados Unidos de hoje, (3) em um "território fronteiriço" (Hogan 1980), de reserva, onde (4) essa população desenvolve, sob coação, uma série de instituições paralelas que servem ao mesmo tempo de substituto funcional às instituições dominantes da sociedade abrangente e de aparato protetor contra elas (Meier e Rudwick 1976; Osofsky 1971). Essas instituições paralelas, no entanto, duplicam as dominantes apenas (5) em um nível incompleto e inferior, mantendo-se o estado de dependência estrutural dos que nelas se apóiam (Spear 1968; Weaver 1968; Fusfeld e Bates 1984; Logan e Molotch 1987). Em outras palavras, o gueto é uma formação étnico-racial que reúne as quatro principais "formas elementares" de dominação racial - o preconceito, a discriminação, a segregação e a violência excludente (Wacquant 1995) - e as inscreve na objetividade do espaço e das instituições específicas do grupo.

O fato de os guetos terem sido historicamente lugares de miséria material endêmica e, às vezes, aguda, não significa que todos os guetos tenham de ser pobres ou igualmente miseráveis. Sem dúvida, a "Bronzeville" dos anos 40 era mais próspera do que as comunidades negras do Sul e provavelmente abrigava a mais numerosa burguesia afro-americana de seu tempo (Drake e Cayton 1962; e, também, Trotter Jr. 1993 para uma discussão mais ampla). Inversamente, nem todas as áreas de baixa renda são guetos, por pior que seja sua miséria. As cidades de maioria branca do Centro-Oeste norte-americano ou dos vales apalachianos, que a desindustrialização tornou decadentes, ou os condados rurais em recessão econômica do delta do Mississipi, as reservas indígenas e os bairros pobres latinos do Sudoeste (para não falar de regiões inteiras do país durante a Grande Depressão) não apresentam o mesmo padrão de organização do dark ghetto: não são, e jamais foram, "colônias filantrópicas, econômicas, mercantis e industriais" da sociedade mais ampla (Clark 1965; e, também, Connolly 1977)5 .

Uma concepção institucionalista (isto é, relacional) do gueto não é apenas mais coerente com as raízes e o uso históricos do termo. Ela também põe em destaque e interroga, de um lado, variáveis que as abordagens mais nominalistas ou gradualistas tendem a tratar como precondições que dispensam maiores investigações - tal como a divisão racial, cujos efeitos estruturais podem variar no tempo mesmo com taxas constantes - e, de outro, acentua a fraca presença e a ineficácia funcional dessas instituições públicas que são dispositivos organizacionais padronizados em outras áreas residenciais urbanas. Acima de tudo, essa con- 
cepção problematiza aquilo que uma perspectiva "demográfica" aceita como evidente: as bases e os mecanismos de triagem que determinam a exclusão no espaço negativamente marcado do gueto. E, em vez de situálo ao longo de distribuições lineares contínuas de renda, moradia, segregação e pobreza, uma abordagem institucionalista procura localizar as rupturas subjacentes ao tecido urbano e refazer as linhas divisórias das quais o gueto é uma manifestação física ${ }^{6}$. É por isso que as fronteiras, a forma, a configuração interna, os vínculos externos e os apoios estruturais do território de exclusão considerado tornam-se questões centrais a serem respondidas pela análise empírica, e não por definição.

\section{Abandonando o tropo da "desorganização"}

Arjun Appadurai (1988) mostrou que determinados lugares tendem a ser progressivamente representados e analisados em termos de "tropos fortes", isto é, conjuntos de imagens e estratégias narrativas recorrentes que predeterminam e distorcem o modo como são percebidos e conceituados. Na sociedade e nas ciências sociais norte-americanas, o "tropo forte" que cerca o gueto, desde a sua origem no final do século passado, é o da "desorganização" ${ }^{7}$.

Desde os primeiros estudos de ecologia humana realizados pela Escola de Chicago, passando pelos trabalhos sobre a crise urbana dos anos 60, até as recentes pesquisas sobre o surgimento da chamada underclass $^{8}$ e suas implicações (Park e Burgess 1920; Wirth 1928; Shaw e McKay 1942; Frazier 1949; Banfield 1970; Wilson 1987; Anderson 1991; Jencks e Peterson 1991), os analistas têm aceito como evidente que o gueto pode ser satisfatoriamente analisado em termos de privação, detalhando suas deficiências, e as de seus moradores, e especificando como (e quanto) se diferenciam da "mainstream" society, avaliada por padrões putativos de "classe média". É significativo que categorias como "mainstream" e "classe média" fiquem geralmente sem definição, de modo a facilitar a ampliação de seus limites para acomodar as necessidades analíticas e ideológicas do momento ${ }^{9}$. Assim sendo, o gueto é tipicamente representado como um lugar de desordem e privação, um depósito de rebeldia, desvio, anomia e atomização concentrados, repleto de comportamentos tidos como ofensivos às normas usuais de moralidade e aceitabilidade, seja por excesso (como acontece com o crime, a sexualidade e a fertilidade), seja por falta (como no caso do trabalho, da poupança e da família). 
Entender o gueto como uma forma institucional, e não como uma acumulação de "patologias", permite o reconhecimento de que ele não sofre de "desorganização social" - conceito moralmente carregado (ver Wirth 1964:44-49) que é melhor eliminar do vocabulário sociológico apesar de sua ilustre linhagem intelectual. Conforme observou William Foote Whyte (1943:273, ênfases minhas), em seu clássico estudo sobre a street-corner society no bairro italiano pobre de Boston, o que um observador de fora entende como desorganização social "muitas vezes revela ser apenas uma forma diferente de organização social, se nos dermos ao trabalho de olhar de perto". Mas, no que se refere ao gueto negro norteamericano, essa observação direta e próxima é exatamente o que tem faltado ao debate recente. Dentre os 27 autores que colaboraram no livro The Urban Underclass (Jencks e Peterson 1991), obra que afirma conter "as melhores e mais recentes pesquisas e reflexões sobre o assunto", apenas um tinha feito pesquisa de campo no gueto. E apenas uns poucos estudos etnográficos dos padrões de vida nos bairros centrais de algumas cidades dos Estados Unidos foram publicados desde as grandes revoltas raciais dos anos $60^{10}$.

A investigação de campo intensiva revela que o gueto, longe de ser des-organizado, organiza-se segundo princípios diferentes, que respondem a uma série de coações estruturais e estratégicas singulares que incidem sobre os enclaves urbanos racialmente estigmatizados de um modo que não ocorre em nenhum outro segmento do território norte-americano (Wacquant 1994). Isso inclui: (1) a pressão inexorável da necessidade econômica e da ampla privação material causada pelo desaparecimento da economia baseada no trabalho assalariado; (2) a profunda insegurança física e social, alimentada pela falência das instituições públicas e o conseqüente enfraquecimento das organizações locais que, por sua vez, fomentam padrões socioculturais irregulares; (3) virulenta hostilidade racial e preconceito de classe que resultam em grave e sistemática redução das oportunidades e dos canais que as propiciam; (4) mácula simbólica e estigmatização territorial reforçadas pela (5) apatia burocrática e inépcia administrativa decorrentes da possibilidade de prescindir eleitoralmente dos negros pobres em um campo político inteiramente dominado pelos grandes interesses corporativos e financeiros.

Hoje em dia, o gueto envolve uma ordem social hobbesiana atravessada pelo conflito permanente e pela competição por recursos escassos (e em diminuição), em um ambiente caracterizado por elevados níveis de desconfiança interpessoal e institucional, uma visão de mundo darwinista, "a lei do mais forte", e uma alta densidade de "predadores sociais" 
(Sánchez-Jankowski 1991:22-28). Essa ordem interna é continuamente reforçada de fora pelo funcionamento rotineiro do Estado e do mercado, e mantida estruturalmente periférica e dependente pela fragmentação das máquinas política e administrativa das metrópoles (Teaford 1990; Weiher 1991). A reconstrução socioanalítica da visão de mundo e das estratégias cotidianas do "malandro" [hustler] profissional do gueto sul de Chicago mostra que a entropia característica da vida nas ruas do gueto tem, de fato, um padrão e obedece a uma lógica social distinta (Wacquant 1993) ${ }^{11}$.

O deslocamento de uma problemática da desorganização para uma problemática da "organização" não se reduz a uma simples mudança de terminologia. Ao contrário, implica uma transformação do objeto a ser construído. Significa que o pesquisador tem de analisar e demonstrar em detalhes o modo concreto como se estruturam as relações sociais e as representações que operam no interior do gueto - o trabalho de autoprodução coletiva, pelo qual seus moradores conferem a seu mundo forma, sentido e propósito - , em vez de apenas constatar que esse modo de autoconstrução é diferente do que governa outros setores da sociedade. Significa também mostrar a maneira como as atividades das instituições dominantes, tais como a burocracia pública e os órgãos de assistência social, as escolas e os hospitais, as associações filantrópicas e as empresas privadas, dão poderosa contribuição para organizar, de forma particularmente desestabilizadora, o espaço social do gueto. Importa, então, reconhecer e especificar a atividade [agency] dos moradores do gueto de tal modo que suas práticas e formas de vida não apareçam como simplesmente derivadas de coações que podem ser "lidas" como condições estruturais, mas como o produto de seu envolvimento ativo com as forças sociais internas e externas que perpassam e modelam seu mundo (Abu-Lughod et alii 1994; Bourgois 1995).

\section{Rompendo com o exotismo}

O tropo da desorganização reforçou a tendência a exotizar o gueto, isto é, a exagerar artificialmente os padrões de conduta e os modos de pensar que mais diferem de uma norma supostamente representativa da sociedade mais ampla, e também, muito freqüentemente, das que prevalecem e são tidas como aceitáveis pelos próprios moradores do gueto ${ }^{12}$. Por essa lógica, os moradores mais pobres, ameaçadores e mal-afamados do núcleo urbano racialmente estigmatizado são caracteristicamente vistos como 
representantes de todo o gueto, e os remanescentes arruinados dos antigos Cinturões Negros dos Estados Unidos, por sua vez, são tidos como aqueles que difamam e contradizem a postura cívica da comunidade negra in toto (Franklin 1992; Fainstein 1995). A conseqüência disso é a permanente re-produção de imagens populares estereotipadas dos negros urbanos - o que Ralph Ellison denominou apropriadamente de "negros préfabricados" —, que ecoam e perpetuam o preconceito racial histórico.

Estudiosos da questão racial e da pobreza têm dedicado uma excessiva atenção às supostas "patologias" dos moradores dos guetos, ou seja, aos comportamentos que a chamada classe média considera anormais, ofensivos ou indevidamente dispendiosos, e que vão desde o crime violento, à "evasão" escolar, à gravidez de adolescentes e à "falta de ambição" na busca de trabalho, até a proliferação de "famílias chefiadas por mulheres", o consumo e o tráfico de drogas e a "dependência da previdência social". Alguns analistas não hesitaram em fundir essas práticas ou status sociais sob o rótulo pejorativo de "comportamentos underclass", enquanto outros foram mais longe ainda e redefiniram o gueto como "uma epidemia de problemas sociais" (Jencks e Peterson 1991:passim)13.

Ora, todo antropólogo está sujeito a "perceber e relatar os comportamentos discrepantes em relação aos de sua própria cultura mais rapidamente e com maior facilidade do que tende a fazer no caso de comportamentos semelhantes àqueles que ela privilegia", tendendo assim a "negligenciar ou menosprezar os elementos da outra cultura que se assemelham aos de sua própria" (Naroll e Naroll 1963:24-26). No caso do gueto, a distância social e cultural entre o analista e o objeto de estudo, o reduzido número de pesquisas de campo aprofundadas e as imagens sociais demoníacas que o encobrem se combinam para ocultar o fato de que formas de organização e ação sociais aparentemente desviantes ou mesmo inexplicáveis quando vistas de longe (ou de cima) obedecem a uma racionalidade social local bem adaptada aos constrangimentos e vantagens da vida real no Cinturão Negro contemporâneo.

Ao mesmo tempo, dizer que uma forma sociocultural segue uma racionalidade localizada não implica, necessariamente, que ela seja específica de um lugar ou grupo determinado: muitas "adaptações" encontradas no gueto não são "especificamente de gueto" [ghetto specific], uma vez que foram observadas tanto entre (sub)proletários nas cidades industriais da Europa ou da América Latina quanto entre jovens operários brancos e de origem latina nos Estados Unidos (p. ex., Perlman 1976; Robins e Cohen 1978; McLeod 1987; Foley 1990; Jones 1992). Mais uma vez, isso significa que a invocação de uma "cultura de gueto", à Hannerz 
(1969), não pode substituir o exame empírico minucioso das microestruturas nas quais se inserem a ação social e a consciência no gueto de hoje.

Para evitar esse bias de exotismo, é indispensável efetuar uma époché moral, suspender o julgamento sobre a (i)moralidade imputada à vida no gueto e focalizar não as práticas mais "espetaculares" e publicamente salientes, mas os atos e as relações mais banais da vida cotidiana, as formas de conduta, percepção e organização aceitas como evidentes, que compõem "a realidade suprema e viva" (Schutz 1962) do gueto como realização estratégica e interpretativa contínua. Ora, afirmar que o gueto é um mundo social "significativo, razoável e normal"14 não é o mesmo que romantizá-lo ou glamourizá-lo. A observação etnográfica não deixa dúvidas de que o gueto é um universo brutal e atormentado por crises, marcado por transgressões, inseguranças, dor e desespero. É apenas pedir que seja tratado com os mesmos princípios analíticos e conceitos usados para entender qualquer outro sistema social, sofisticado ou não, glamouroso ou desprezível, familiar ou estranho, harmonioso ou hostil. Estudos sobre guerras, campos de concentração, prisões ou catástrofes naturais (Browning 1992; Pollak 1991; Sykes 1971; Erikson 1978) revelam que, até nas situações mais extremas, a vida social obedece a uma regularidade, segue um padrão e contém uma lógica e um significado acessíveis à compreensão analítica.

A tarefa da sociologia, portanto, é a de desvendar a necessidade social imanente que governa as práticas e as formas de vida dos moradores do gueto, e não a de participar na construção de um novo "orientalismo urbano" - no sentido de Edward Said - em que a underclass seria a figura de proa. Em suma, devemos seguir a advertência formulada por Everett C. Hughes (1980:99) em sua penetrante discussão das "instituições bastardas" — das quais o gueto seria um exemplo primordial — de que elas

“[...] deveriam ser estudadas não como meros afastamentos patológicos do que é bom e certo, mas como partes integrantes da totalidade complexa das atividades e empreendimentos humanos. Além disso, deveriam ser encaradas como ordens de coisas em que podemos observar os processos sociais em ação, os mesmos processos que, talvez, sejam encontrados nas instituições legítimas". 
Loïc Wacquant é professor-associado de Sociologia na Universidade da Califórnia, Berkeley, e pesquisador-associado do Centro de Sociologia Européia do Collège de France. É doutor em Sociologia pela Universidade de Chicago. Seus campos de interesse incluem a marginalidade urbana comparada, a raça como princípio de visão e divisão social, cultural e econômica, e o corpo. E-mail: loic@uclink2.berkeley.edu

\section{Notas}

1 Um grande número de estudos sobre esse assunto poderia ser mencionado. Basta citar, porém, o trabalho de Jencks e Peterson (1991), que reúne exemplos paradigmáticos dessas crenças. Isso não implica que a literatura das ciências sociais sobre raça e pobreza urbana seja monolítica (ver Wilson e Aponte 1985; Marks 1991; e Devine e Wright 1993, para resenhas gerais), mas sim que as variações existentes se mantêm dentro do espaço analítico definido por esses três compromissos pré-conceituais.

2 Como Wittgenstein (1977:17) observou certa vez: "O que torna um assunto difícil de entender - se for uma coisa importante e significativa — não é que, antes de entendê-lo, você precise ter recebido instrução especializada em temas abstrusos, mas o contraste entre o entendimento do assunto e o que a maioria das pessoas quer ver. É por isso que as coisas mais óbvias podem ser as mais difíceis de compreender. A dificuldade a superar está mais ligada à vontade do que ao intelecto".

3 Sobre a singularidade, intensidade e persistência da segregação dos negros ao longo dos cem anos de existência do gueto, ver: Spear (1968); Farley e Allen (1987); Jaynes e Williams Jr. (1989); Hirsch (1993); e Massey e Denton (1993).

4 Para uma descrição detalhada e convincente dos princípios básicos do institucionalismo (e do neo-institucionalismo) na tradição sociológica, ver DiMaggio e Powell (1992). Para uma exposição do conceito de fechamento e seu uso nas teorias weberiana e neoweberiana das classes e da desigualdade entre grupos, ver Brubaker (1991:1aㅡ parte); Murphy (1988); e Parkin (1978).

5 Para uma descrição da localização e das estruturas ecológica, social e institucional dos bairros latinos pobres nas metrópoles norte-americanas, que chama a atenção para as diferenças com os núcleos negros urbanos, ver Moore e Pinderhughes (1993).

6 Para um estudo exemplar da produção sociopolítica de clivagens urbanas como um processo mais institucional do que ecológico, ver a reconstrução de Abu- 
Lughod (1980) do "apartheid urbano do Marrocos" e a transmutação da divisão de castas em linhas de classe na Rabat pós-colonial.

7 Ver Ward (1989) para uma longa análise das continuidades e das mudanças na caracterização social de favelas, guetos e outros territórios de exclusão urbana na era da expansão do capitalismo industrial. Alphabet City, de Geoffrey Biddle (1992), oferece uma brilhante e atualizada ilustração fotográfica da perspectiva da "desorganização" aplicada ao setor porto-riquenho do Lower East Side de Nova Iorque.

8 Underclass é um termo originalmente cunhado pelo economista sueco Gunnar Myrdal durante os anos 60, que se tornou popular na mídia e no debate social público durante os 80 , que designa uma subseção dos pobres supostamente caracterizada ao mesmo tempo pela baixa renda e por "comportamentos disfuncionais". O termo não tem equivalente em outros idiomas, na medida em que reflete a particular concepção norte-americana sobre pobreza e raça. Para uma genealogia e uma crítica desse termo e seu uso acadêmico, ver Wacquant (1996a).

9 Um uso representativo dessa dualidade típica do senso comum é o comentário de Jencks (1991:218-251) sobre "As mães underclass em oposição às mães mainstream". Em outro trabalho, Jencks (Jencks e Peterson 1991:28-29) reconhece que, embora "haja uma aceitação geral de que 'underclass' é um antônimo de 'classe média', ou mesmo, em um sentido mais amplo, de 'mainstream' (palavra que passou a englobar a classe média e a classe operária)", acontece "que os americanos nunca estiveram de acordo sobre o que quer dizer classe média ou classe operária". Por isso, os conceitos básicos em torno dos quais se organiza seu rigoroso exame do "crescimento da underclass americana" são prejudicados por uma confusão epistêmica e uma indeterminação semântica. Jencks prossegue, confessando que a conformidade à moda acadêmica é que o autoriza a usar essa noção semijornalística, semi-especializada: "A meu juízo, mudanças sociais [relevantes] não são suficientemente grandes para justificar a substituição do termo underclass pelo de classe baixa. Mas como quase todo mundo fala hoje em dia mais de underclass do que de classe baixa, faço a mesma coisa" (Jencks e Peterson 1991:28).

10 Além dos trabalhos de Elijah Anderson (1991), Martín Sánchez-Jankowski (1991), Philippe Bourgois (1995) e Mercer Sullivan (1989), os relatos mais informativos sobre a vida cotidiana do gueto negro de hoje não são de autoria de cientistas sociais, mas de jornalistas. Dentre estes, os estudos de Sylvester Monroe e Peter Goldman (1988); Alex Kotlowitz (1991); Laurie K. Abraham (1993); e William M. Adler (1995).

11 A respeito da racionalidade da estrutura social e da ação em favelas, ver, por exemplo, as análises pioneiras de Portes (1972) e Perlman (1976) e a pesquisa que realizaram sobre a marginalidade urbana na América Latina.

12 Esse bias de exotismo é muito antigo e persistente, como assinala Ulf Hannerz (1970:313): “Desde os primeiros estudos sobre negros nas Américas, os pes- 
quisadores têm feito comentários a respeito da maneira como o comportamento de homens e mulheres negros - especialmente alguns homens e mulheres difere da conduta dos brancos".

13 O trabalho de Jonathan Crane (1991) é um exemplo caricato desse moralismo superficialmente disfarçado pela retórica e pelos dados da ciência social, que, inacreditavelmente, conseguiu ser publicado na American Journal of Sociology, explicitando claramente as implicações políticas e morais desse tipo de pesquisa. Como mostrou Sassier (1990), do século XVI ao século XX, os discursos sobre a pobreza têm sempre refletido não a condição e o estado dos próprios pobres, mas as principais desordens políticas do período tal qual percebidas pelas elites sociais e intelectuais.

14 Como nos lembra Erving Goffman (1961:7) na introdução de Asylums, “todo grupo de pessoas - prisioneiros, primitivos, pilotos ou pacientes - desenvolve uma vida própria que se torna significativa, razoável e normal quando olhada de perto". Dizer que um mundo social é "normal" não implica que seus participantes o experimentem ou aceitem como tal, como demonstra o exemplo dos campos de concentração. Para uma narrativa etnográfica que busca comunicar as formas de sociabilidade e a tessitura das formas de expressão cultural por meio das quais os moradores do gueto produzem a "normalidade" (ou estrutura social em linguagem etnometodológica) de seu mundo cotidiano, a despeito da decadência e da insegurança circundante, ver Wacquant (1996b). 


\section{Referências bibliográficas}

ABRAHAM, Laurie K. 1993. Mama Might Be Better Off Dead: The Failure of Health Care in Urban America. Chicago: The University of Chicago Press.

ABU-LUGHOD, Janet. 1980. Rabat: Urban Apartheid in Morocco. Princeton: Princeton University Press. et alii. 1994. From Urban Village to East Village. Oxford: Basil Blackwell.

ADLER, William M. 1995. Land of Opportunity: One Family's Quest for the American Dream in the Age of Crack. New York: The Atlantic Monthly Press.

ANDERSON, Elijah. 1991. Streetwise: Race, Class, and Change in an Urban Community. Chicago: The University of Chicago Press.

APPADURAI, Arjun. 1988. "Putting Hierarchy in its Place". Cultural Anthropology, 3(1):36-49.

BACHELARD, Gaston. 1938. La Formation de l'Esprit Scientifique. Contribution à une Psychanalyse de la Connaissance Objective. Paris: Libraire Philosophique J. Vrin.

BANFIELD, Edward C. 1970. The Unheavenly City. New York: Free Press.

BIDDLE, Geoffrey. 1992. Alphabet City. Berkeley: University of California Press.

BOURGOIS, Philippe. 1995. In Search of Respect: Selling Crack in El Barrio. Cambridge: Cambridge University Press.

BOYER, Paul. 1978. Urban Masses and Moral Order in America, 1820-1920. Cambridge: Harvard University Press. BROWNING, Christopher R. 1992. Ordinary Men: Reserve Police Battalion
101 and the Final Solution in Poland. New York: Harper Perennial.

BRUBAKER, William R. 1991. Traditions of Citizenship and Nationhood in France and Germany. Ph.D. Dissertation, Columbia University.

CLARK, Kenneth B. 1965. Dark Ghetto: Dilemmas of Social Power. New York: Harper.

CONNOLLY, Harold X. 1977. A Ghetto Grows in Brooklyn. New York: New York University Press.

COOPERMAN, Bernard e CURIEL, Roberta. 1990. The Venetian Ghetto. New York: Rizzoli International Publications.

CRANE, Jonathan. 1991. "The Epidemic Theory of Ghettos and Neighborhood Effects on Dropping Out and Teenage Childbearing". American Journal of Sociology, 96(5):12261259.

DEVINE, James A. e WRIGHT, James D. 1993. The Greatest of Evils: Urban Poverty and the American Underclass. New York: Aldine.

DIMAGGIO, Paul J. e POWELL, Walter W. 1992. "Introduction". In: W. W. Powell e P. J. DiMaggio (eds.), The New Institutionalism in Organizational Analysis. Chicago: The University of Chicago Press. pp. 1-38.

DRAKE, St. Clair e CAYTON, Horace R. 1962 [1945]. Black Metropolis: A Study of Negro Life in a Northern City. New York: Harper and Row. 2 vols. (edição revisada e ampliada).

ERIKSON, Kai T. 1978. Everything in its Path. New York: Vintage.

FAINSTEIN, Norman. 1995. "Black Ghettoization and Social Mobility". In: M. Smith e J. Feagin (eds.), The Bubbling Cauldron: Race, Ethnicity, 
and the Urban Crisis. Minneapolis: University of Minnesota Press. pp. 123-141.

FARLEY, Reynolds e ALLEN, Walter R. 1987. The Color Line and the Quality of Life in America. New York: Russell Sage Foundation.

FISHMAN, Robert. 1988. Bourgeois Utopias: The Rise and Fall of Suburbia. New York: Basic Books.

FOLEY, Douglas. 1990. Learning Capitalist Culture: Deep in the Heart of Tejas. Philadelphia: University of Pennsylvania Press.

FRANKLIN, Raymond. 1992. Shadows of Race and Class. Minneapolis: University of Minnesota Press.

FRAZIER, E. Franklin. 1949. The Negro in the United States. New York: MacMillan.

FUSFELD, Daniel e BATES, Timothy. 1984. The Political Economy of the Ghetto. Carbondale: Southern Illinois University Press.

GOFFMAN, Erving. 1961. Asylums: Essays on the Social Situation of Inmates. Harmondsworth: Penguin.

HANNERZ, Ulf. 1969. Soulside: Inquiries into Ghetto Culture and Community. New York: Columbia University Press.

1970. "What Black Males Are Like: Another Look". In: N. E. Whitten e J. F. Szwed (eds.), Afro-American Anthropology: Contemporary Perspectives. New York: The Free Press. pp. 313-327.

HIRSCH, Arnold R. 1993. "With or Without Jim Crow: Black Residential Segregation in the United States". In: A. R. Hirsch e R. A. Mohl (eds.), Urban Policy in Twentieth-Century America. New Brunswick: Rutgers University Press. pp. 64-94.

HOGAN, Richard. 1980. "The Frontier as Social Control". Theory and Society, 14:35-51.
HUGHES, Everett C. 1980. The Sociological Eye. New Brunswick: Transaction.

JARGOWSKI, Paul A. e BANE, Mary Jo. 1991. "Ghetto Poverty in the United States, 1970-1980". In: C. Jencks e P. E. Peterson (eds.), The Urban Underclass. Washington, D.C.: The Brookings Institution. pp. 235-273.

JAYNES, Gerald D. e WILLIAMS JR., Robin M. 1989. A Common Destiny: Blacks and American Society. Washington, D.C.: National Academy Press. JENCKS, Christopher. 1991. Rethinking Social Policy: Race, Poverty, and the Underclass. Cambridge: Harvard University Press. e PETERSON, Paul E. (eds.). 1991. The Urban Underclass. Washington, D.C.: The Brookings Institution.

JONES, Jacqueline. 1992. The Dispossessed: America's Underclasses from the Civil War to the Present. New York: Basic Books.

KATZ, Michael. 1983. Poverty and Policy in American History. New York: Academic Press.

KOTLOWITZ, Alex. 1991. There Are No Children Here. New York: Doubleday.

LOGAN, John R. e MOLOTCH, Harvey L. 1987. Urban Fortunes: The Political Economy of Place. Berkeley: The University of California Press.

MARKS, Carole. 1991. "The Urban Underclass". Annual Review of Sociology, 17:445-466.

MASSEY, Douglas e DENTON, Nancy. 1993. American Apartheid: Segregation and the Making of the Underclass. Cambridge: Harvard University Press.

MCLEOD, Jay. 1987. Ain't No Makin' It. Boulder: Westview Press.

MEIER, August e RUDWICK, Elliott. 1976. From Plantation to Ghetto. New York: Hill and Wang. 
MONROE, Sylvester e GOLDMAN, Peter. 1988. Brothers: Black and Poor - A True Story of Courage and Survival. New York: William Morrow.

MOORE, Joan e PINDERHUGHES, Raquel (eds.). 1993. In the Barrio: Latinos and the Underclass Debate. New York: Russell Sage Foundation.

MURPHY, Raymond. 1988. Social Closure: The Theory of Monopolization and Exclusion. Oxford: Clarendon Press

NAROLL, Raoul e NAROLL, Frada. 1963. "On Bias of Exotic Data". Man: A Monthly Record of Anthropological Science, 63:24-26.

OSOFSKY, Gilbert. 1971. Harlem: The Making of a Ghetto - Negro New York, 1890-1930 (2a ed.). New York: Harper.

PARK, Robert E. e BURGESS, Ernest. 1920. The City. Chicago: The University of Chicago Press.

PARKIN, Frank. 1978. Marxism and Class Theory. New York: Columbia University Press.

PATTERSON, James. 1986. America's Struggle against Poverty. Cambridge: Harvard University Press.

PERLMAN, Janice. 1976. The Myth of Marginality. Berkeley: The University of California Press.

POLLAK, Michael. 1991. L'Expérience Concentrationnaire. Paris: A.-M. Métailié.

PORTES, Alejandro. 1972. "Rationality in the Slum: An Essay in Interpretative Sociology". Comparative Studies in Society and History, 14(3): 268-286. ROBINS, David e COHEN, Philip. 1978. Knuckle Sandwich: Growing Up in the Working-Class City. Harmondsworth: Penguin Books.

SÁNCHEZ-JANKOWSKI, Martín. 1991. Islands in the Street: Gangs in Urban American Society. Berkeley: University of California Press.
SASSIER, Philippe. 1990. Du Bon Usage des Pauvres. Histoire d'un Thème Politique, XVIe-XXe. Siècle. Paris: Fayard.

SCHUTZ, Alfred. 1962. Collected Papers I: The Problem of Social Reality. The Hague: Martinus Nijhoff.

SHAW, Clifford e MCKAY, Henry. 1942. Juvenile Delinquency in Urban Areas. Chicago: The University of Chicago Press.

SPEAR, Allan H. 1968. Black Chicago: The Making of a Negro Ghetto, 1890-1920. Chicago: The University of Chicago Press.

SULLIVAN, Mercer. 1989. Getting Paid: Youth Crime and Work in the Inner City. Ithaca: Cornell University Press.

SYKES, Gresham M. 1971. The Society of Captives: A Study of a Maximum Security Prison. Princeton: Princeton University Press.

TEAFORD, Jon C. 1990. The Rough Road to Renaissance: Urban Revitalization in America, 1940-1985. Baltimore: The Johns Hopkins University Press.

TROTTER JR., William J. 1993. “Blacks in the Urban North: The 'Underclass Question' in Historical Perspective". In: M. B. Katz (ed.), The "Underclass" Debate: Views from History. Princeton: Princeton University Press. pp. 55-81.

WACQUANT, Loïc J. D. 1991. What Makes a Ghetto? Notes Toward a Comparative Analysis of Modes of Urban Exclusion. Trabalho apresentado no seminário Poverty, Immigration and Urban Marginality in Advanced Societies. Maison Suger, Paris, 10-11 de maio.

.1993. “'The Zone': Le Métier de 'Hustler' dans le Ghetto Noir Américain". In: P. Bourdieu et alii, La Misère du Monde. Paris: Editions du Seuil. pp. 181-204. 
1994. "The New Urban Color Line: The State and Fate of the Ghetto in Postfordist America". In: C. J. Calhoun (ed.), Social Theory and the Politics of Identity. Oxford/Cambridge: Basil Blackwell. pp. 231-276. . 1995. Elementary Forms of Racial Domination. Palestra realizada no Núcleo da Cor. Instituto de Filosofia e Ciências Sociais/UFRJ, Rio de Janeiro, 10 de outubro.

. 1996a. "L'Underclass Urbaine' dans l'Imaginaire Social et Scientifique Americain". In: S. Payman (ed.), L'Exclusion: L'État des Savoir. Paris: Editions La Decouvert. pp. 248-262.

.1996b. "Un Mariage dans le Ghetto". Actes de la Recherche en Sciences Sociales, 113:63-84.

WARD, David. 1989. Poverty, Ethnicity, and the American City, 1840-1925. Cambridge: Cambridge University Press.

WEAVER, Robert. 1968. The Negro Ghetto. New York: Russell and Russell.

WEBER, Max. 1978 [1818-22]. Economy and Society. Berkeley: University of California Press.

WEIHER, Gregory. 1991. The Fractured Metropolis: Political Fragmentation and Metropolitan Segregation. Albany: State University of New York Press.

WHYTE, William Foote. 1943. Street Corner Society: The Social Structure of an Italian Slum. Chicago: The University of Chicago Press.

WILSON, William J. 1987. The Truly Disadvantaged: The Inner City, the Underclass and Public Policy. Chicago: The University of Chicago Press.

e APONTE, Robert. 1985. "Urban Poverty" . Annual Review of Sociology, 11:231-258.

WIRTH, Louis. 1928. The Ghetto. Chicago: The University of Chicago Press.
1964. On Cities and Social Life (editado e com introdução de Albert J. Reiss Jr.). Chicago: The University of Chicago Press.

WITTGENSTEIN, Ludwig. 1977. Vermischte Bermerkungen. Frankfurt: Suhrkamp. 


\section{Resumo}

Este artigo é um exame crítico de três premissas que dominaram e viciaram o debate recente sobre divisão racial e pobreza urbana nos Estados Unidos: a) diluir a noção de gueto fazendo-a designar simplesmente uma área urbana de intensa pobreza, o que obscurece a base racial da pobreza e despe o termo de seu significado histórico e de seus conteúdos institucionais; b) a idéia de que o gueto é uma formação social "desorganizada" que pode ser analisada em termos de falta e deficiências, sem identificar os princípios subjacentes à sua ordem interna; c) exotizar o gueto e seus moradores, ou seja, enfatizar os aspectos mais extremos e não usuais da vida no gueto tal qual vista de fora e de cima, isto é, do ponto de vista dos dominantes. Dotadas de plausibilidade pelo peso da história cultural e reforçadas por um idioma nacional individualista que eufemiza o poder de classe e a dominação étnico-racial, essas premissas constituem um formidável "obstáculo epistemológico" para uma adequada construção do gueto como objeto científico.

\section{Abstract}

This article offers a critical examination of three premises that have dominated and vitiated the recent debate on racial division and urban poverty in the United States: a) to dilute the notion of ghetto simply to designate an urban area of intense poverty, which obscures the racial basis of this poverty and divests the term of both historical meaning and institutional contents; b) the idea that it is a "disorganized" social formation that can be analyzed in terms of lack and deficiencies rather than by identifying the principles that underlie its internal order; $\mathrm{c}$ ) to exoticize the ghetto and its residents, that is, to spotlight the most extreme and unusual aspects of ghetto life as seen from outside and above, i.e., from the standpoint of the dominant. Endowed with plausibility by the weight of cultural history, reinforced by an individualistic national idiom that euphemizes class power and ethnoracial domination, these premises form a formidable "epistemological obstacle" to an adequate construction of the ghetto as a scientific object. 